Dai J, Yang W, Cao J, Liu D, Long X.

Ageing assessment of a wind turbine over time by interpreting wind farm

SCADA data.

Renewable Energy 2017,

https://doi.org/10.1016/j.renene.2017.03.097

\section{Copyright:}

(C) 2017. This manuscript version is made available under the CC-BY-NC-ND 4.0 license

DOI link to article:

https://doi.org/10.1016/i.renene.2017.03.097

Date deposited:

$18 / 04 / 2017$

Embargo release date:

31 March 2018

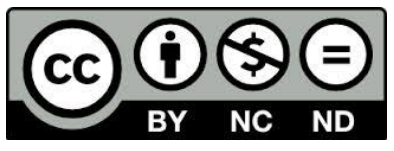

This work is licensed under a

Creative Commons Attribution-NonCommercial-NoDerivatives 4.0 International licence 


\title{
Ageing Assessment of a Wind Turbine over Time by Interpreting Wind
} Farm SCADA Data

\author{
Juchuan Dai ${ }^{\mathrm{a}, \mathrm{b}}$, Wenxian Yang ${ }^{\mathrm{b}, \mathrm{c}}$, Junwei Cao ${ }^{\mathrm{a}}$, Deshun Liu ${ }^{\mathrm{a}}$, Xing Long ${ }^{\mathrm{d}}$ \\ ${ }^{\text {a }}$ School of Electromechanical Engineering, Hunan University of Science and Technology, Xiangtan 411201, \\ China \\ ${ }^{\mathrm{b}}$ School of Engineering, Newcastle University, Newcastle upon Tyne NE1 7RU, UK \\ ${ }^{c}$ Hunan Province Cooperative Innovation Centre for Wind Power Equipment and Energy Conversion, Hunan \\ Institute of Engineering, Xiangtan 411104, China \\ ${ }^{\mathrm{d}}$ XEMC Windpower Co., Ltd., Xiangtan 411000, China
}

\begin{abstract}
Ageing of a wind turbine and its components is inevitable. It will affect the reliability and power generation of the turbine over time. Therefore, performing the ageing assessment of wind turbines is of significance not only to optimize the operation and maintenance strategy of the wind turbine but also to improve the management of a wind farm. However, in contrast to the significant number of research on wind turbine condition monitoring and reliability analysis, little effort was made before to investigate the ageing led performance degradation issue of wind turbines over time. To fill such a technology gap, four SCADA-based wind turbine ageing assessment criteria are proposed in this paper for measuring the ageing resultant performance degradation of the turbine. With the aid of these four criteria, a reliable information fusion based wind turbine ageing assessment method is developed and verified in the end using the real wind farm SCADA data. It has been shown that the proposed method is effective and reliable in performing the ageing assessment of a wind turbine.
\end{abstract}

Keywords: Wind turbines; Ageing assessment; Performance degradation; SCADA data

\section{Introduction ${ }^{1}$}

With the rapid development of wind power industry, there is an increasing need to lower the Cost of Energy (COE) of wind power [1]. In recent years, effort has been made to develop advanced condition monitoring and maintenance optimization techniques in order to improve the safety and availability of wind turbines, such as the advanced condition monitoring techniques developed based on wavelet transform [2] and wavelet-transform [3, 4]; the condition-based maintenance strategies [5]; and son on. The research results do significantly improve the operation and maintenance activities in wind farms. For example, based on a robust fault reconstruction technique the considered faults and system states are simultaneously reconstructed [6]. In the meantime, to better manage the wind power assets, a number of reliability related research, including reliability-centered maintenance (RCM) analysis [7], reliability analysis with incomplete failure data[8], reliability analysis based on failure modes and effects analysis[9], were also

\footnotetext{
Corresponding author. Tel +44(0)1912086171
} 
conducted to understand the reliability of wind turbines and their components. The interesting findings from these analyses do provide a global view of the reliability issues existing in the present wind industry, which is very helpful not only to improve the reliability design of the turbine but also to develop right insurance policies for wind power facilities. In summary, all these previous efforts on both condition monitoring and reliability analysis actually accelerate the development of wind power industry. However, the ageing effect, which not only affects energy capture[10], but also affects the reliability and operation of wind turbines, has not been fully paid attention to. The designed life of a wind turbine is normally 20-25 years for onshore and 25-30 years for offshore. During the service period, it is inevitable that the reliability and performance of the turbine will degrade over time due to ageing effect. Such degradation will more or less reduce the performance of the turbine. However, it is still not a fault because it does not affect delivering the normal function of any wind turbine component. Since the conventional wind turbine condition monitoring techniques are usually focused on fault detection and diagnosis[11, 12], therefore not ideal for dealing with this kind of ageing issues. So far, research on the wind turbine ageing issue has not been reported in the open literature, although it does accompany the service of a wind turbine. Moreover, harsh operational environments (e.g. the wet and corrosive offshore environment) and aggressive loading conditions (e.g. the loads induced by turbulent wind and storm) can accelerate the ageing issues. Therefore, it is of great significance to carry out the ageing assessment, which will benefit the life management of a wind turbine and thereby maximize its economic return. The preliminary research reported in this paper is just in order to reach such a purpose.

Wind farms are equipped with supervisory control and data acquisition (SCADA) system, which collects data from critical components of wind turbines in order to understand turbines' operational condition and control them from distance in the case of necessity. In recent years, the added value of wind farm SCADA data is further explored in the field of wind turbine condition monitoring. For example, a fault prediction method was proposed and some datamining algorithms were used to develop models predicting potential faults in [13]; wind turbine gearbox was monitored through analyzing lube oil and bearing temperature data in [14]; SCADA-based clustering and principal component analysis were used for diagnosing gearbox failure in [15]; multivariate state estimation technique and moving window calculation were used to estimate the wind turbine gearbox temperature in [16]; a multi-agent system architecture was used to corroborate various interpretation technique output, provide performance evaluation and early fault identification in [17]; adaptive neuro-fuzzy interference system was used to develop SCADA-based wind turbine condition monitoring system in [18, 19]; an effective SCADA data processing method and the associated quantitative health condition assessment method were developed in [20]; the inner-DBSCAN (density-based spatial clustering of applications with noise) algorithm for monitoring the wind turbine operation condition was developed in [21]. However, almost all these research are linked to condition monitoring, fault diagnosis and fault prediction of wind turbines. The effort for dealing with the ageing issues of wind turbines is still insufficient. As mentioned in [20, 22, 23] , SCADA data are not ideal for conducting a full condition monitoring of a wind turbine due to their low sampling frequency. But they could be more suitable to be applied to investigate the ageing led performance degradation issues of a wind turbine as the low-sampling-rated SCADA data can describe the performance of a wind turbine in a long time. This is why wind farm SCADA data is used in this paper to develop the ageing assessment technique for wind turbines.

In summary, the key scientific contributions of this paper are 
- A feasible method of performing ageing assessment of wind turbines using wind farm SCADA is proposed following the discussion of a number of SCADA parameters that can indicate the ageing of different wind turbine components;

- A more reliable information fusion based method is further developed to assure the reliability of ageing assessment conclusion.

\section{SCADA parameters for ageing assessment}

SCADA data are the data collected from the key components of wind turbines by wind farm SCADA system, which include a number of parameters, reflecting the operation and status of the turbines in the wind farm. But in practice, the SCADA parameters being collected from different concepts of wind turbines may be different. For example, the turbines considered in this paper are gearless direct-drive permanent magnet wind turbines. The SCADA data collected from them include wind speed, rotor speed, pitch angle, nacelle vibration, wind direction, yaw angle, generator power, generator current, generator frequency, generator torque, hub azimuth, converter current, converter pressure, converter temperature, hub temperature, temperature of the main bearing, power of pitch motor, hydraulic brake pressure, etc. All these parameters are important to ensure the safety and efficient operation of the turbines. However, not all of them are really useful for conducting the ageing assessment. Therefore, the useful SCADA parameters for conducting wind turbine ageing assessment will be identified first from these data in this research. Then, a few ageing assessment criteria will be designed based on the identified SCADA parameters specifically for assessing the performance degradation of the key parts of the wind turbine being investigated.

\subsection{Modelling output power}

The stability of output power at corresponding wind speed is one of the important criteria for assessing the performance of a wind turbine. The assessment is based on the following two assumptions, i.e. (1) under the same operational and weather condition (i.e. wind speed, wind direction, temperature, humidity etc.), the power generated by the wind turbine at the corresponding wind speed should be approximately same; (2) when wind speed is above the rated wind speed, the output power should be constantly close to the rated power of the turbine despite the change of operational and weather conditions. If presuming the yaw angle of the nacelle is always right, then, in theory, the fluctuation of output power is basically dependent on the variations of air density, wind speed, rotor speed, and pitch angle of rotor blade, as shown in equation (1) [24, 25].

$$
\Delta P=\frac{1}{2}(\rho+\Delta \rho)(v+\Delta v)^{3} \pi R^{2} \cdot C_{p}\left(\frac{(\omega+\Delta \omega) R}{v+\Delta v},(\beta+\Delta \beta)\right)
$$

where, $\Delta$ indicates fluctuation, $P$ refers to the output power, $\rho$ is air density, $v$ is air velocity, $R$ is rotor diameter, $C_{p}$ is power coefficient, and $\beta$ is the pitch angle of the blade. Among these variables, rotor speed $\omega$ and pitch angle $\beta$ can be controlled based on requirements, while wind speed and air density are uncontrollable.

From (1), it can be inferred that the amount of power fluctuation under different operational and weather conditions will be different. For this reason, to ensure the reliability of the assessment, the method that is used for evaluating the power fluctuation should be less dependent or independent of the weather and operational conditions of the turbine. In order to try best to meet such a requirement, in this paper, the power fluctuation is investigated only when the wind speed is above the rated wind speed. This is because the pitch control system of the wind turbine starts to work only when wind speed is above the rated wind speed. In this scenario, through blade pitch control, the output power from 
wind turbine generator is constrained around the rated power in spite of the change of wind condition. By contrast, the pitch control system of the wind turbine will not work when wind speed is below the rated wind speed. As shown in Fig.1, to reach a constant output power, the blade pitch control system of a variable speed wind turbine will be trigged on as soon as the measured power exceeds the power demand. Then, the output power will be controlled by adjusting the pitch angle of the blade $\beta$, which will influence the aerodynamic characteristics of the wind turbine as long as the turbine converter can successfully fix the rotational speed of turbine rotor. In other words, assume the power electronic convert of the turbine works properly, the rotor speed in this region will be almost constant (i.e. $\Delta \omega \rightarrow 0)$. Then, the power fluctuation $\Delta P$ will mainly rely on the accuracy of blade pitch control. Accordingly, the output power fluctuation $\Delta P$ is used in this paper mainly to reflect the ageing issue of blade pitch control system, which has shown lots of reliability issues in wind farm. But it is worthy to note that such a strategy is subject to that the wind turbine converter is in good condition and is able to carry out a perfect control of rotor speed.

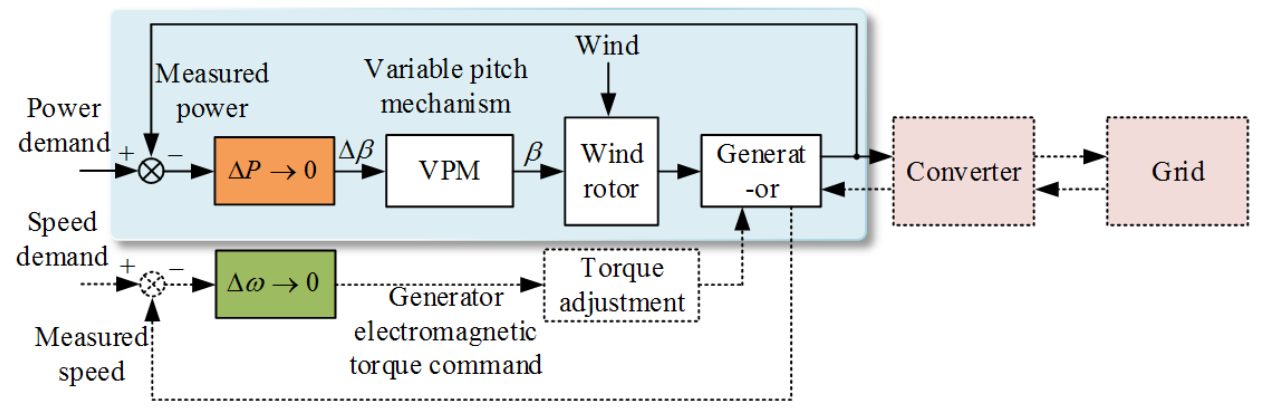

Fig.1 Power control structure of wind turbines when wind speed is above the rated wind speed

\subsection{Power coefficient}

Power coefficient $C_{p}$ is a criterion indicating the capability of the wind turbine in capturing and converting aerodynamic energy in wind to electric power. In SCADA system, the collected power is the power output of the wind turbine generator rather than the energy of all wind flowing into the wind turbine rotor, so the power coefficient can be mathematically expressed as

$$
C_{p}=\frac{P}{W}=\frac{2 P}{\rho v^{3} \pi R^{2}}
$$

where, $W$ is the total aerodynamic energy of the wind passing through the sweep area of the wind turbine rotor; $P$ is output power of the generator.

From (2), it can be inferred that if overlooking the ignorable energy loss that is consumed by wind turbine drive train and control system, the value of $C_{p}$ is affected mainly by the aerodynamic performance of wind turbine rotors and the energy conversion efficiency of the generator. For a permanent magnet generator, the degradation of the latter can be induced by either the demagnetization of magnetic material or the ageing issues of wires.

The relationship between the aerodynamic characteristics of wind rotor (lift and drag coefficients of airfoil sections) and the energy that it can capture from the wind is expressed as $[25,26]$

$$
P=\omega \int_{0}^{R} \frac{1}{2} \rho c \frac{v_{0} \omega r^{2}(1-a)\left(1+a^{\prime}\right)}{\sin \phi \cos \phi}\left(C_{l} \sin \phi-C_{d} \cos \phi\right) d r
$$

where, $\omega$ is rotor speed; $r$ stands for the distance of an airfoil section from the root of the blade; $C_{l}$ and $C_{d}$ are respectively the lift and drag coefficients of the airfoil; $v_{0}$ is the axial wind velocity; $a$ and $a^{\prime}$ are axial and tangential 
induced velocity coefficients, respectively; $\phi$ is inflow angle; $c$ is chord length of the airfoil.

From (3), it can be seen that the value of $P$ is dependent on lift coefficient, drag coefficient, and induced velocity coefficient and in turn, any change of these three parameters due to blade damage will significantly affect the value of $P$.

As the SCADA data used in this paper are from permanent magnet synchronous direct drive wind turbines, herein the ageing issue of the permanent magnet generator is considered. The power generated by a permanent magnet generator can be expressed as [27-29]

$$
P=\frac{3}{2} p\left[\psi_{f} i_{s q}+\left(L_{s d}-L_{s q}\right) i_{s d} i_{s q}\right] \omega
$$

where, $p$ is the number of pole pairs; $\psi_{f}$ is the permanent magnet magnetic field; $i_{s d}$ and $i_{s q}$ are $d$ axis and $q$ axis components of stator currents, respectively; $L_{s d}$ and $L_{s q}$ are $\mathrm{d}$ axis and $q$ axis inductances of the stator, respectively.

It is necessary to note that the model shown in (4) uses the $d$ - $q$ rotating coordinate system on the rotor as the reference coordinate system, the $d$ axis is directed to the rotor pole axis, and the $q$ axis is ahead of the $d$ axis for 90 electric angles. From Eq. (4), it is clearly seen that with the increase of service time, the decreased permanent magnet magnetic field $\psi_{f}$ will have a direct impact on output power.

For the aforementioned reasons derived from (3) and (4), power coefficient $C_{p}$ is used in this paper to indicate the performance degradation of wind turbine blade and generator.

\subsection{Nacelle vibration}

Nacelle vibration can be excited by many factors. Apart from being affected by external loads, the vibration measured from wind turbine nacelle is also influenced by the integrity of the tower and other support and fixture structures of the turbine. Once the stiffness and damping of these structures change due to ageing, the vibration of the nacelle will increase over time. The external loads acting on wind turbines are mainly from the wind. According to the BEM theory, the axial force acting on the blades is $[25,26,30]$

$$
d N=\frac{1}{2} \rho c \frac{v_{0}^{2}(1-a)^{2}}{\sin ^{2} \phi}\left(C_{l} \cos \phi+C_{d} \sin \phi\right) d r
$$

where, $d N$ is the axial force acting on the blades.

Despite the rich number of excitations, the nacelle vibration can be simply manifested using a mechanical dynamics model as shown in Fig.2. Once ageing happens during the service, the structural stiffness and damping will deviate from their original states, which will consequently lead to the change in nacelle vibration. Such a process can be simply expressed as

$$
m a x=F_{N}
$$

where, $F_{N}$ represents the exciting load.

Based on this consideration, the nacelle vibration is used in this paper to describe the performance degradation of the tower and other support and fixture structures of wind turbines. 


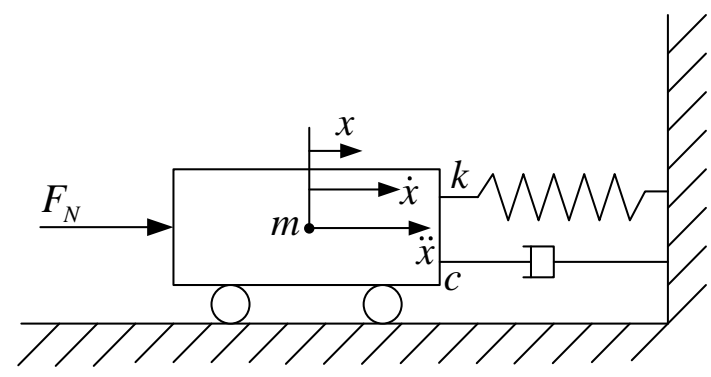

Fig.2 Mass-spring-damping model of the nacelle

\subsection{Key component temperature}

The temperature of the main bearing, which is one of the key components of wind turbines, is monitored by wind turbine SCADA system. Besides the presence of defect, the bearing temperature can be influenced also by external loads, the quality of lubrication oil, the condition of bearing components, the axis electric current, environmental temperature, etc., see Fig.3. Over the course of service, both the physical properties of lubrication oil and the worn state of bearing components will change due to ageing issues and moreover, the external fatigue loads and axis electric current can accelerate the change. Consequently, the bearing cannot run efficiently anymore when ageing effect becomes significant. Hence, more energy loss will occur in bearing operation, part of which will be present in the thermal form, i.e. temperature. Therefore, the temperature of the main bearing will increase to a certain extent when ageing effect becomes significant. For this reason, the bearing temperature is used in this paper as a criterion to indicate the ageing issue of the wind turbine main bearing.

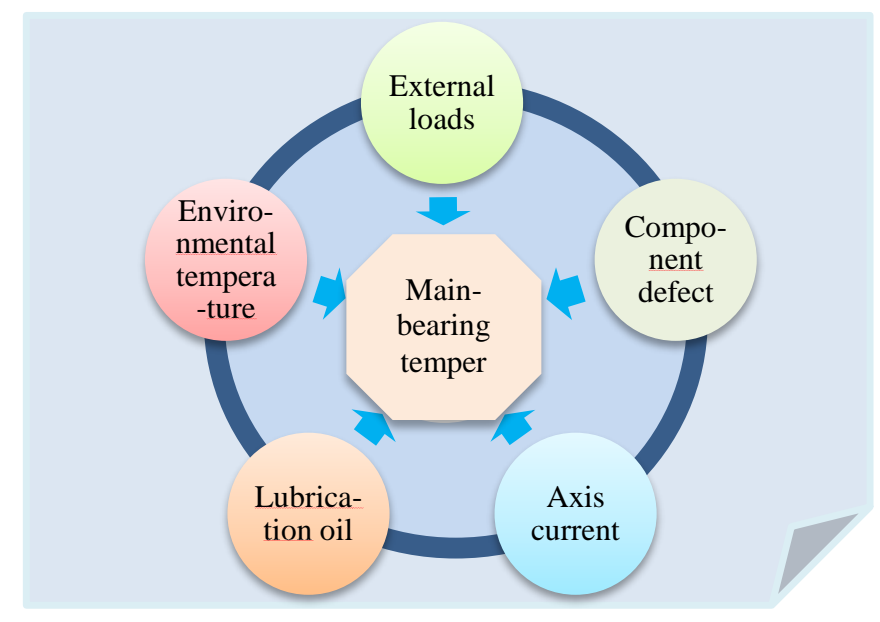

Fig.3 Influence factors of main bearing temperature

\section{Ageing assessment method}

To implement successful ageing assessment, it is critical to design reliable assessment criteria based on the four SCADA parameters identified in Section 2. However, the relevant research has never been reported in previous literature. The work presented in this section is in order to fill such a technology gap.

\subsection{Assessment criteria}

\section{(1) Criterion for characterizing the fluctuation of output power}

A criterion is proposed to characterize the fluctuation of output power in the scenario when the wind speed is above the rated wind speed. It can be calculated by following the steps:

i) Data preparation. As shown in Section 2.1, the output power data used for assessing the fluctuation are only those collected when the wind speed is above the rated wind speed. Moreover, in order to assure the accuracy of the 
evaluation, the invalid data (e.g. null data, singularity data, etc.) and those measured when the turbine is faulty and at standby should be taken out first before the calculation. After preparing the data using such a method, the trimmed data used for fluctuation assessment can be expressed as

$$
D_{k}=\left[v_{k i}, P_{k i}\right] \quad(i=1,2, \cdots, n)
$$

where, $\quad v_{k i}>v_{\text {rate }}, \quad v_{\text {rate }}$ represents the rated wind speed; $k$ indicates the sample number; $n$ indicates the total number of data obtained after filtering during a certain period.

Then the absolute fluctuation of the output power $\Delta P$ during the period could be characterized by the standard deviation of the output power, i.e.

$$
\Delta p_{k}=\sqrt{\frac{1}{n} \sum_{i=1}^{n}\left(P_{i}-\bar{P}\right)^{2}}
$$

where, $\bar{P}$ stands for the average of $P_{i}$. Herein, a big value of $\Delta p_{k}$ will indicate a large fluctuation of the output power.

Assume the SCADA data available for this assessment contain $N$ sets of data, i.e. $\boldsymbol{D}=\left\{D_{1}, D_{2}, \cdots, D_{N}\right\}$, then a series of data $\Delta \boldsymbol{P}=\left\{\Delta p_{1}, \Delta p_{2}, \cdots, \Delta p_{N}\right\}$ can be obtained in the end. In fact, in addition to the standard deviation, some other methods, e.g. $\Delta P_{k}=\max \left(P_{i}\right)-\min \left(P_{i}\right)$, are also feasible for describing power fluctuation. They all can be used for ageing assessment.

ii) Reliable estimation of output power fluctuation. In order to assure the reliability of assessment, the calculated set of data $\Delta \boldsymbol{P}=\left\{\Delta p_{1}, \Delta p_{2}, \cdots, \Delta p_{N}\right\}$ are further processed with the aid of Kernel Density Estimation (KDE) [3133]. The kernel density estimation can be implemented by

$$
\hat{f}_{h}(x)=\frac{1}{N h} \sum_{i=1}^{N} K\left(\frac{x-X_{i}}{h}\right)
$$

where, $K(\cdot) \geq 0$ is a kernel function, which satisfies the condition of $\int_{-\infty}^{+\infty} K(x) d x=1$. In this paper, the Gaussian function $K(u)=e^{-0.5 u^{2} / \sqrt{2 \pi}}$ is used as the kernel function for calculation. $X_{i}$ is the element contained in $\Delta P$. Parameter $h$ refers to window width to ensure the estimated kernel density curve $\hat{f}_{h}(x)$ can best fit the distribution of $\Delta P$.

Let the variable $x$ in (8) changes continuously from $\min (\Delta P)$ to $\max (\Delta P)$ and substitute the elements of $\Delta P$ into (8), a kernel density curve, as shown in Fig.4, can be obtained. Then, the expected value of $\Delta p$ can be readily determined from the kernel density curve. It is the value of ' $x$ ' that corresponds to the maximum value of $\hat{f}_{h}(x)$.

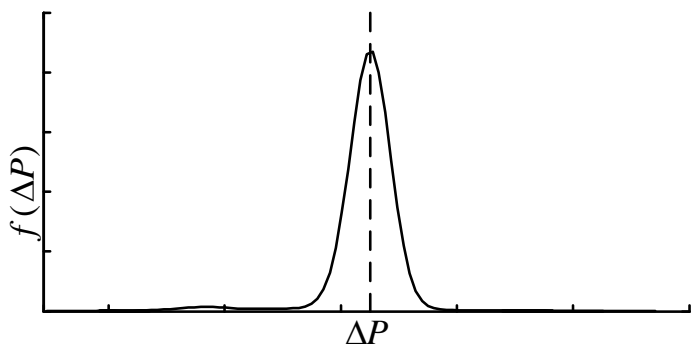

Fig.4 Estimated output power fluctuation through kernel density analysis

iii) Criterion for assessing the ageing of wind turbine control system. To assess the performance degradation of the wind turbine control system due to the effect of ageing, the following criterion $\delta_{p}$ is developed, i.e. 


$$
\delta_{p}=\frac{\Delta P_{T}}{\Delta P_{B}}
$$

where, $\Delta P_{B}$ is the benchmark value of the output power fluctuation obtained when the wind turbine is at its early service life, $\Delta P_{T}$ is the current value of the output power fluctuation.

\section{(2) Criterion for characterizing the change of power coefficient}

Since the wind turbine works with different values of power coefficient at different operation stages, it is necessary to think about which stage is most appropriate for performing the assessment of the ageing resultant change of power coefficient. Therefore, a schematic power generation diagram of the wind turbine is plotted in Fig.5.

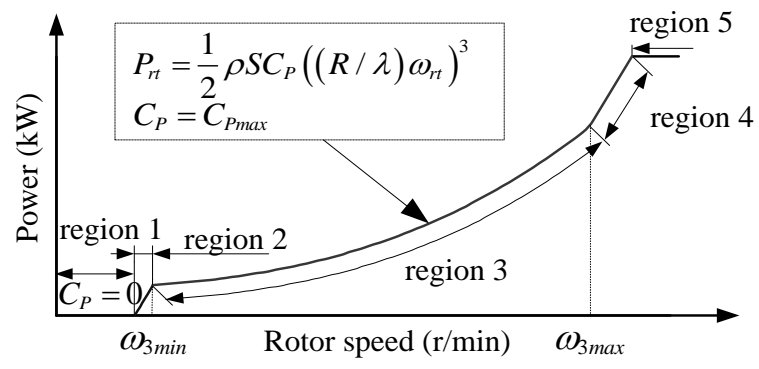

Fig.5 Relationship between rotor speed and power [34]

From Fig.5, it can be seen that the operation of the turbine consists of 5 stages, namely starting (region 1), first transition (region 2), maximum power point tracking (region 3), second transition (region 4), and full power (region 5). Although SCADA data are collected from all regions in Fig.5, a specific region will be deliberately selected when calculating an individual criterion. Since power coefficient is almost constant in region 3, the data collected in which are used to reach a reliable estimation of the change of power coefficient. In contrast, in the other regions, the value of power coefficient varies over time with the change of wind speed. As a consequence, it is unlikely to reach a reliable estimation of the change from such data.

The theoretical maximum value of power coefficient $C_{P}$ of a wind turbine has been defined at the design stage and the turbine is deemed to keep tracking of it when operating in region 3. When a fault occurs in the turbine, the measured value of $C_{P}$ will drop down. But this does not mean that in region 3, the $C_{P}$ value is constantly the maximum value in the absence of a fault. The value of $C_{P}$ will change in a large range when the turbine performance degrades over time due to the ageing of key components (e.g. blade and generator). This is why $C_{P}$ is selected as a criterion for assessing the performance degradation of wind turbine rotor blades and generator. To obtain a reliable assessment, the following computing algorithm is developed.

i) Data preparation. To fully avoid the negative influences of unstable wind speed and downtime of the turbine on calculation results, the SCADA data (i.e. wind speed $v$, rotor speed $\omega$ and generator output power $P$ ) collected in region 3 are sorted using rotor speed. Such a data sorting strategy is based on the fact that the turbine can generate electric power only when its rotor is running despite the value of wind speed. Following this method, in a certain time period, a number of SCADA data that are valid for this assessment can be readily obtained. They are

$$
Y_{k}=\left[v_{k i}, \omega_{k i}, P_{k i}\right], \quad(i=1,2, \cdots n)
$$

where, $k$ indicates the order of time period; $n$ is the number of data collected during the period. Herein, rotor speed 
varies in the range of $\left[\omega_{3 \min }, \omega_{3 \max }\right]$, where $\omega_{3 \min }$ and $\omega_{3 \max }$ are respectively the minimum and maximum rotor speeds in region 3.

ii Reliable estimation of power coefficient. Due to the inertia of turbine rotor, the output power cannot give an immediate response to the change of wind speed. For this reason, it is not rational to calculate $C_{p}$ directly using (2). Therefore, an improvement was made, i.e.

where all relevant data in a time period $\left[t_{1}, t_{2}\right]$, rather than only the instant values of $P$ and $v$ measured at a specific moment, are used for the calculation. Thus, the calculated result by (10) can better reflect the actual power coefficient of the turbine than equation (2) does. In the calculation, air density $\rho$ is dependent on temperature, humidity and atmospheric pressure in the wind farm, i.e.[35]

$$
\rho=\frac{p_{m a}}{R_{d a} T}\left[1-0.378 \frac{\varphi p_{s}(t)}{p_{m a}}\right]
$$

where, $R_{d a}$ is dry air constant; $\varphi$ is the relative humidity of the air; $p_{s}(t)$ is the water vapor saturation pressure when the temperature is $t, \mathrm{~Pa} ; p_{m a}$ is the pressure of the moist air, $\mathrm{Pa}$.

In practical calculation, the power coefficient is estimated using the following discrete form, i.e.

$$
C_{P}(k)=\frac{\sum_{i=1}^{n} P(k T)}{\sum_{i=1}^{n} \frac{1}{2} \rho v(k T)^{3} \pi R^{2}}
$$

Assume the SCADA data collected in $N$ time periods, i.e. $\boldsymbol{Y}=\left\{Y_{1}, Y_{2}, \cdots, Y_{N}\right\}$, are valid for performing this assessment, then a series of calculation results of $C_{p}$ can be obtained, i.e. $\boldsymbol{C}_{P}=\left\{C_{P 1}, C_{P 2}, \ldots, C_{P N}\right\}$. Then, the KDE method illustrated in (8) will be used to further improve the reliability of the estimation result of power coefficient. Likewise, the $x$ value at which the maximum value of the nuclear density occurs is regarded as the final assessment result of the $C_{p}$ during the whole testing period.

iii ) Criterion for assessing the ageing of power dependent components. To assess the performance degradation of the wind turbine blade and generator, the following criterion $\delta_{\mathrm{Cp}}$ is developed, i.e.

$$
\delta_{C p}=\frac{C_{P B}}{C_{P T}}
$$

where $C_{P B}$ is the benchmark value of the power coefficient obtained when the wind turbine is at its young age, $C_{P T}$ is the power coefficient that the wind turbine exhibits at present.

From (13), it can be inferred that the more the value of $\delta_{C p}$ deviates from 1, the more serious the turbine

\section{(3) Criterion for characterizing the change of nacelle vibration}

During the operation of a wind turbine, the vibration of the nacelle is constantly monitored by the SCADA system. Assume the nacelle vibrations measured in horizontal and vertical directions are respectively $a_{x}$ and $a_{y}$, then the ageing resultant performance degradation of wind turbine structure can be inferred from $a_{x}$ and $a_{y}$. The method 
developed for performing such an assessment is shown in the following.

i) Data preparation. Nacelle vibration data of the wind turbine at rated wind speed is selected as

$$
Z_{k}=\left[v_{k}, a_{x k}, a_{y k}\right]
$$

where, $v_{k}=v_{\text {rated }}, k=1,2, \cdots, N$ indicates the number of each sample data.

ii) Reliable estimation of nacelle vibration. Using the data $a_{x k}$ and $a_{y k}$ that are measured in two mutually perpendicular directions, the synthetic vibration of wind turbine nacelle can be readily derived, i.e.

$$
a_{k}=\sqrt{a_{x k}^{2}+a_{y k}^{2}}
$$

Thus, a series of nacelle synthetic vibration data $\boldsymbol{a}=\left\{a_{1}, a_{2}, \cdots, a_{N}\right\}$ can be obtained in the end. Then, apply the KDE method described by (8) to identifying the reliable synthetic vibration of the wind turbine nacelle $Z_{i}$, which corresponds to the peak value on the kernel density curve. Herein, subscript ' $i$ ' indicates the KDE resultant reliable nacelle synthetic vibration obtained from the data measured in the $i^{\text {th }}$ time period. Assume the nacelle vibration data used for the ageing degradation assessment are measured respectively during $M$ time periods, then a series of reliable nacelle vibration data $\boldsymbol{Z}=\left\{Z_{1}, Z_{2}, \cdots, Z_{M}\right\}$ can be obtained at last.

iii ) Criterion for assessing the ageing of structures. To assess the ageing led degradation of wind turbine tower and other support structures of wind turbines, the following criterion $\delta_{a}$ is developed, i.e.

$$
\delta_{a}=\frac{\tilde{z}}{Z_{b}}
$$

where $Z_{b}$ is the benchmark value of nacelle vibration obtained when the wind turbine is normally operating at its

\section{(4) Criterion for characterizing the variation of main bearing temperature}

In the practice of wind power generation, the operating temperature of the wind turbine main bearing is monitored usually by a pair of temperature sensors that are symmetrically installed on the bearing. To achieve a reliable ageing assessment result, only those temperature data collected at the rated wind speed and the same environmental temperature are used to perform the assessment. It is understandable that when comparing the same criterion obtained in different time periods, the constraint conditions should be same. However, the constraint conditions cannot be absolutely consistent. Furthermore, except the external environmental conditions, the wind turbine running mode (for example, down power regulation mode) can affect the bearing temperature. In order to minimize the impact of the kind of uncertainties on the reliability of the assessment result, in addition to defining a specific operating condition in which the assessment is undertaken, the collected data will be further processed using KDE (Kernel Density Estimation) method in the paper to assure a reliable assessment. Assume the temperature measurement results by the two sensors are respectively $T_{a}$ and $T_{b}$, then the method for characterizing the temperature variation can be described as follows.

i) Data preparation. Considering the bearing temperature can be different under different loading and operating conditions of the turbine, the temperature data used for this assessment are collected only when wind speed reaches the rated wind speed. Accordingly, the following set of data $W_{k}$ is obtained over the course of the $k^{\text {th }}$ time period, i.e.

$$
W_{k}=\left[v_{k}, T_{a k}, T_{b k}\right]
$$


collected respectively by the two sensors during the $k^{\text {th }}$ time period. Repeat the data collection and finally obtain $N$ sets of data for assessment, i.e. $\boldsymbol{W}=\left\{W_{1}, W_{2}, \cdots, W_{N}\right\}$.

i i ) Reliable estimation of temperature. Use arithmetic average method to process $T_{a k}$ and $T_{b k}$, has

$$
T_{k}=\frac{T_{a k}+T_{b k}}{2}
$$

Apply (16) to processing all $N$ sets of data, then a series of data $\boldsymbol{T}=\left\{T_{1}, T_{2}, \cdots, T_{N}\right\}$ can be obtained in the end.

Likewise, apply the KDE method to process data $\boldsymbol{T}$ to obtain the reliable estimation of main bearing temperature $T_{T}$ through detecting the peak value on the resultant kernel density curve.

iii ) Criterion for assessing the ageing of main bearing. To assess the performance degradation of wind turbine main bearing due to the effect of ageing, the following criterion $\delta_{t}$ is developed, i.e.

$$
\delta_{t}=\frac{T_{T}}{T_{B}}
$$

where $T_{B}$ is the benchmark value of main bearing temperature obtained when the wind turbine normally operates at its young age.

\subsection{Ageing assessment methods}

Based on the four assessment criteria proposed above, there are the following two optional methods can be used to assess the ageing resultant performance degradation issue of the wind turbine over time.

(1) Conventional method

The method achieves the assessment by respectively investigating the variation tendency of each criterion over time. Therefore, the deviation of any one of the four criteria from its benchmark value will imply the presence of ageing degradation in the turbine performance. Accordingly, the larger deviation indicates a worse ageing issue. Such a method is simple and easy to implement. Moreover, it can help us to identify readily the wind turbine subassemblies that are suffering more ageing issue. However, such a method can hardly provide a reliable description of the ageing situation of the whole turbine system. To address this issue, the sum of all four criteria was proposed to be a new criterion for ageing assessment, i.e.

$$
\delta=\delta_{p}+\delta_{C p}+\delta_{a}+\delta_{t}
$$

However, such a method treats the four performance assessment criteria equally without any identification, which could lead to unreliable assessment due to unreasonably amplifying or weakening the roles of the four criteria in ageing assessment.

(2) Information fusion method

The long-term wind farm practice has shown that the aforementioned four assessment criteria play different roles in reflecting the overall performance of the wind turbine. Therefore, they should be treated differently. For this reason, the first information fusion based method shown in (18) is further improved by assigning an appropriate weighting factor to each criterion, i.e.

$$
\left\{\begin{array}{l}
\delta=r_{1} \cdot \delta_{p}+r_{2} \cdot \delta_{C p}+r_{3} \cdot \delta_{a}+r_{4} \cdot \delta_{t} \\
r_{1}+r_{2}+r_{3}+r_{4}=1
\end{array}\right.
$$

where $r_{1}, r_{2}, r_{3}$ and $r_{4}$ are the weighting factors being assigned respectively to the four assessment criteria. 
Since the values of four criteria are all equal to 1 in the absence of ageing, the value of the comprehensive ageing criterion should normally be equal to 1 . Its value will deviate from 1 once ageing happens on the turbine. Undoubtedly, the application of these four weighting factors is helpful to reach a more reliable ageing assessment result. However, how to determine the appropriate values of these four weighting factors, in reality, is challenging. Up to date, there is no any relevant research has been reported in open literature. To address this issue, a deliberately designed questionnaire is assigned to four experienced engineers, who all have been working in the field of wind farm operation and maintenance for over 15 years. The questionnaire was designed to ask the interviewees to answer a few small questions regarding the influences of the ageing of different wind turbine components/subassemblies on the power generation performance of the turbine. The influences were marked with the values scaling from 1 to 10 . Then, after receiving the completed questionnaire these values will be normalized to obtain the corresponding values of weighting factors through assuming the sum of these weighting factors is equal to 1 . The survey results received from these four engineers are listed in Table 1.

Table 1. Weighting factors assigned to the four ageing assessment criteria

\begin{tabular}{c|cccc}
\hline Criterion & $\begin{array}{c}\text { Power } \\
\text { fluctuation } \\
\text { weight } r_{1}\end{array}$ & $\begin{array}{c}C_{p} \text { weight } \\
r_{2}\end{array}$ & $\begin{array}{c}\text { Vibration } \\
\text { weight } r_{3}\end{array}$ & $\begin{array}{c}\text { Temperature } \\
\text { weight } r_{4}\end{array}$ \\
\hline expert1 & 0.2 & 0.5 & 0.2 & 0.1 \\
expert2 & 0.1 & 0.4 & 0.2 & 0.3 \\
expert4 & 0.1 & 0.5 & 0.2 & 0.2 \\
average value & 0.1 & 0.5 & 0.1 & 0.3 \\
\hline
\end{tabular}

From Table 1, it is clearly seen that the weights of the four assessment criteria from different experts are more or less different. Nevertheless, their consensus is that in contrast to power fluctuation, nacelle vibration, and main bearing temperature, power coefficient $C_{p}$ is more alert to the performance degradation of the turbine due to ageing issue. Therefore, in order to highlight the engineers' researchers' consensus whilst also fully take into account their dissent, the values that they proposed to each weighting factor are averaged in this paper for further calculations. They are $r_{1}=0.125, r_{2}=0.475, r_{3}=0.175$ and $r_{4}=0.225$, respectively.

\section{Verification of the proposed method}

Since the ageing of a wind turbine is characterized by the gradual degradation of its performance change (e.g. power coefficient change) over time, it is taken for granted that the ageing effect of a turbine can be assessed through observing the developing tendency of the criterion being investigated.

Based on the above discussion, the calculations and analyses for performing the proposed ageing assessment is summarized in Fig.6. To demonstrate the verification steps, a 2MW direct-drive wind turbine is selected as an example (called unit \#1), which was installed in 2011. SCADA data collected from this wind turbine respectively in March 2015 and January 2016 are used. The sampling frequency of the SCADA system is 1Hz. The wind speed and corresponding power fluctuation data collected in an interval are shown in Figs.7a and $7 \mathrm{~b}$. There is a total of $1.7 \times 10^{4}$ 
sets of data are used for performing power fluctuation assessment. When investigating the fluctuation of power, wind speeds should be basically same in order to ensure that the estimation is conducted under the 'basically same' control and operational conditions, so that a more reliable estimation can be reached. Subsequently, Eq. (7) is used to calculate the power fluctuation criterion when $n=10$. The value of parameter $n$ takes into account the influences of the inertia of rotor, the characteristics of the generator and the control of the turbine. Due to the inertia of rotor, both rotor speed and the power generated by the wind turbine generator are unable to respond to the instantaneous change in wind speed [30]. Then, the histograms of the absolute fluctuation of the output power $\Delta P$ and the resultant kernel density curves are obtained. The results are shown in Figs.8a and 8b.

404

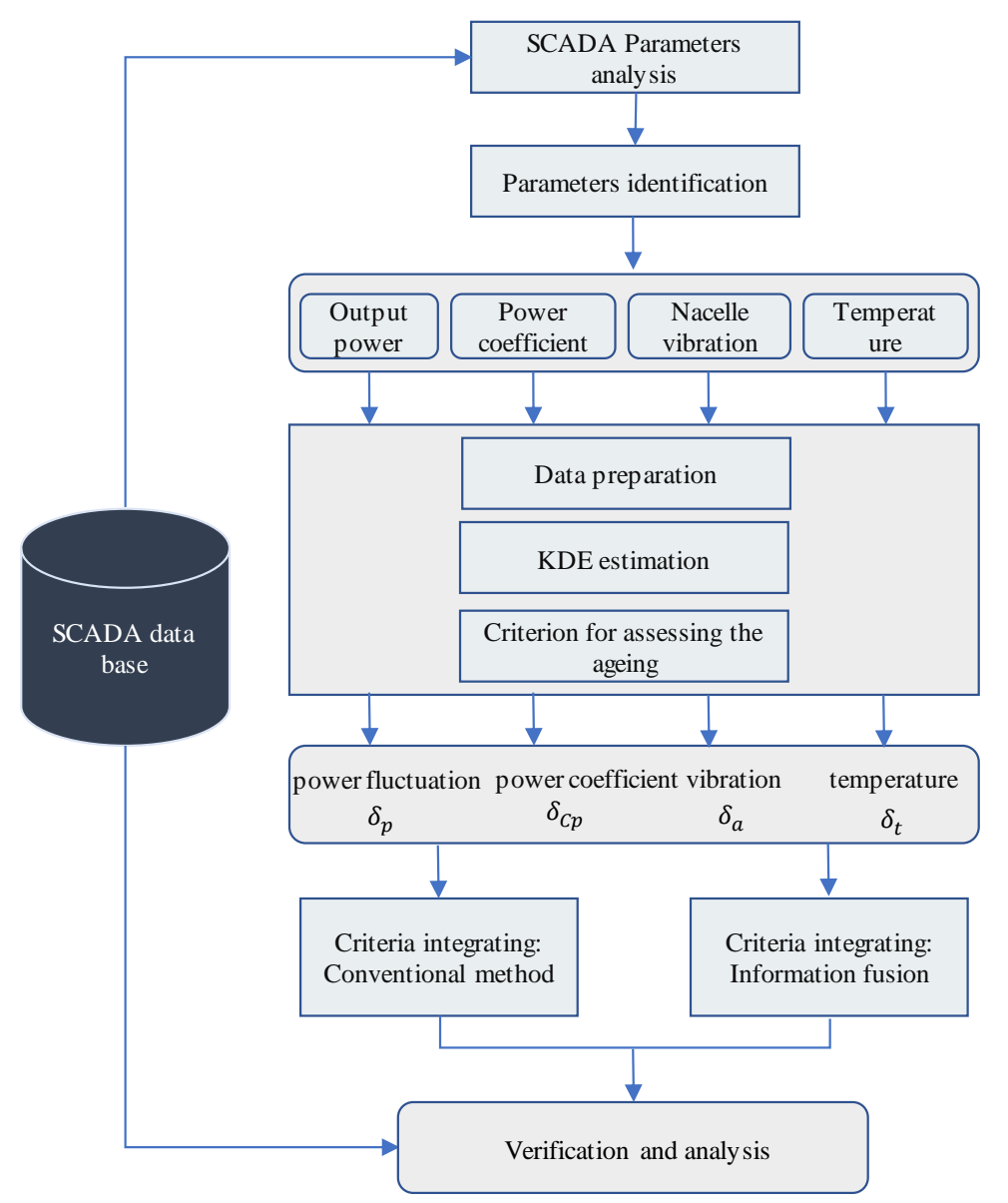

Fig.6 Flow chart of the proposed calculations and analyses for ageing assessment

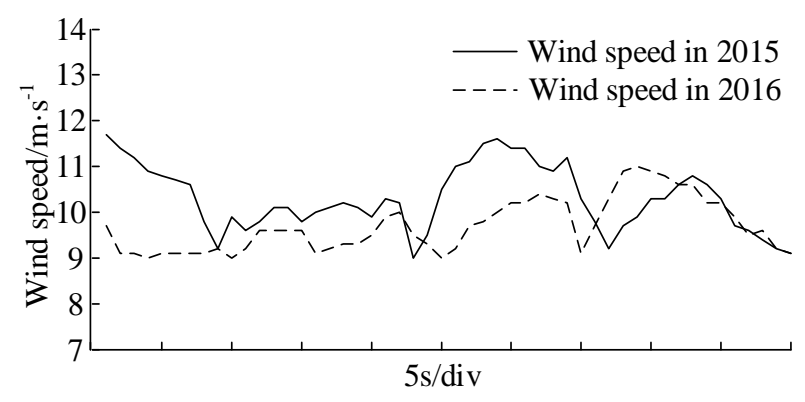

(a) Wind speed 


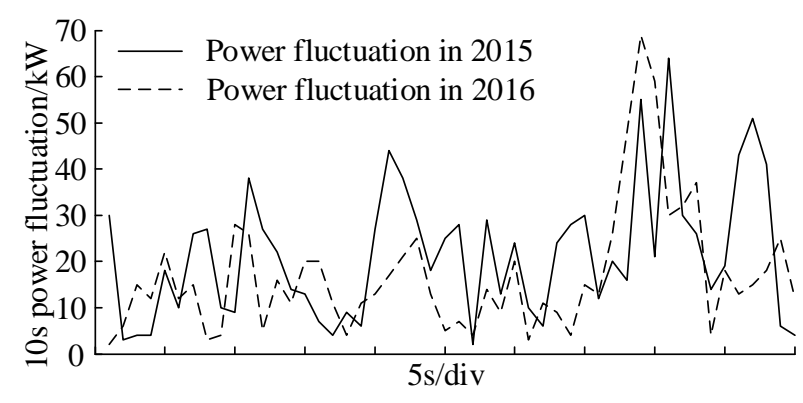

(b) Power fluctuation

Fig.7 Wind speed and power fluctuation in a sampling interval

Fig. 8 (a) is for the data collected in 2015 and Fig.8 (b) is for the data collected in 2016, respectively. From the kernel density curve, it is known that the reliable value of the power fluctuation in 2015 is $14.5 \mathrm{~kW}$, while the reliable value in 2016 is lowered down to $13 \mathrm{~kW}$. Since $\mathrm{KDE}$ has given the corresponding data value with the maximum probability, this result is robust to the uncertainty existing in SCADA data. Subsequently, take the reliable estimation of the power fluctuation in 2015 as the benchmark value $\Delta P_{B}$ and apply (9) to calculate the power fluctuation criterion $\delta_{p}$. The result is $\delta_{p}=0.897$. This seems to indicate the ageing effect on output power fluctuation in the past one year. However, the common sense is that it is unlikely that the turbine will show so significant ageing effect in one year time.

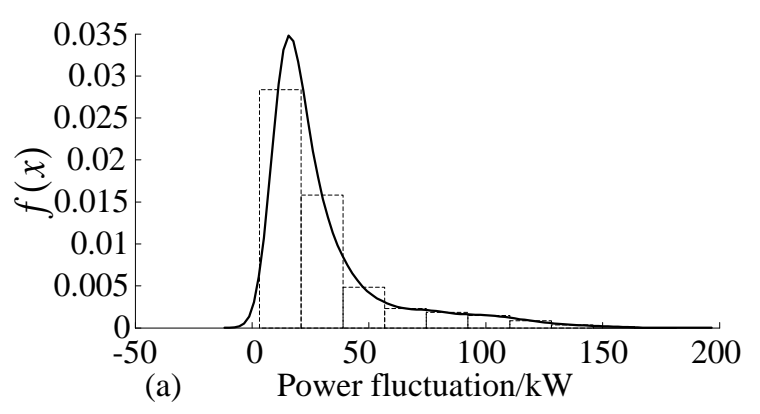

Fig.8 Histogram and kernel density estimation of power fluctuation

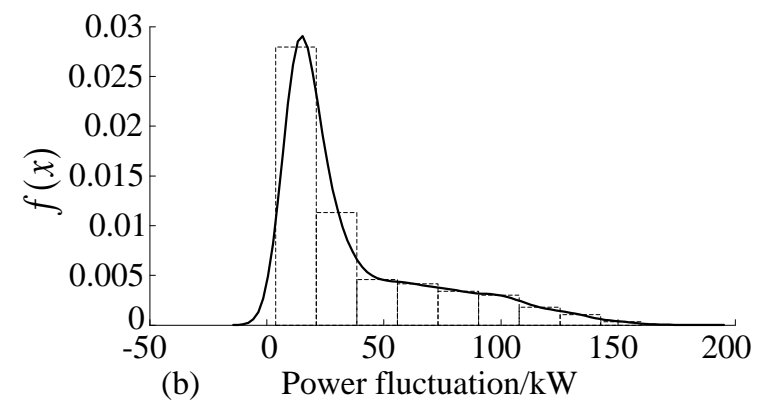

(b)

Subsequently, the ageing effect on wind turbine power coefficient was also investigated. There are total $1.8 \times 10^{4}$ sets of data are collected. According to the recorded wind farm temperature, humidity, and atmospheric pressure data, the air density is calculated first using (11). The result is about $1.226 \mathrm{~kg} / \mathrm{m}^{3}$ in data selection period in 2015 and 1.243 $\mathrm{kg} / \mathrm{m}^{3}$ in 2016, respectively. Then, use (12) to calculate power coefficient $C_{p}$. The histograms of the calculated $C_{p}$ and the corresponding kernel density curves for both time periods are shown in Figs.9a and 9b. From Figs.9a and 9b, it is found that the calculated value of power coefficient varies in a wide range. However, in theory it should be constant because the SCADA data used for this calculation was from the maximum power point tracking (MPPT) region (see Fig.5), in which the wind turbine power coefficient is constantly equal to the maximum value of power coefficient $C_{p \max }$. This is normal because the actual wind speed constantly varies time by time, which leads instantaneous change of the calculated power coefficient. In other words, the operation of the wind turbine cannot exactly follow the instantaneous change of wind speed. Thus, calculation errors occur inevitably in Figs.9a and $9 \mathrm{~b}$. Anyway, the application of KDE can significantly minimize the unreliability of estimation. From Figs.9a and 9b, it is found that the reliable estimation values of the power coefficient are 0.356 in 2015 and 0.327 in 2016. Then, take 
the value obtained in 2015 as the benchmark value, apply (13) to calculate the criterion $\delta_{C p}$. The result is $\delta_{C p}=1.089$, which deviates from 1 . Thus, it seems to indicate a significant ageing effect on power coefficient in one year.

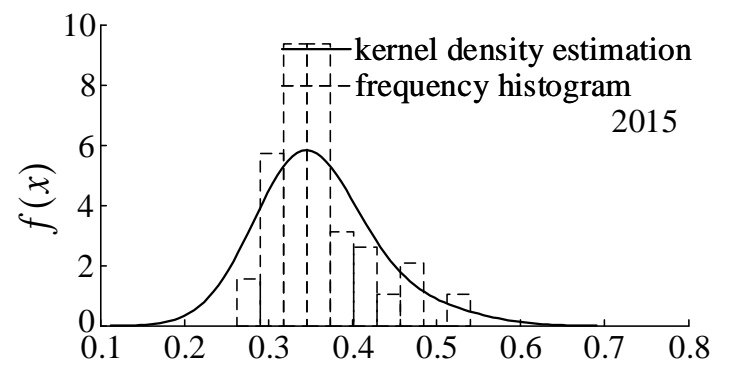

(a)

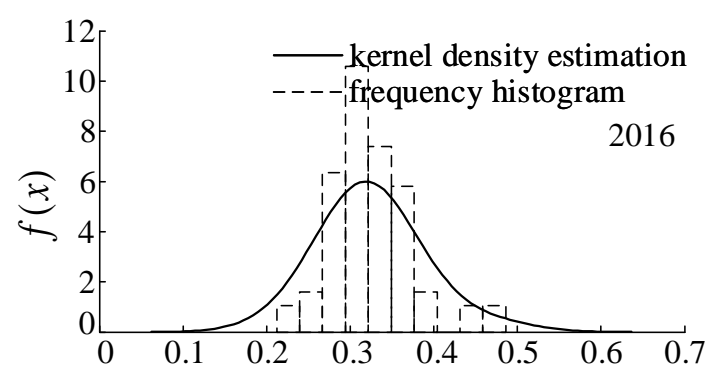

(b)

Power coefficient

Fig.9 Histogram and kernel density estimation of power coefficient

Likewise, use the proposed methods and the data collected $\left(1.7 \times 10^{4}\right.$ sets of data) in 2015 and 2016 to calculate the changes of nacelle vibration and main bearing temperature as well. The resultant histograms and the corresponding kernel density curves are shown in Figs.10a and 10b and Figs.11a and 11b, respectively. From the figures, it is known that the reliable estimation of the nacelle vibration $a$ in 2015 is $0.19 \mathrm{~m} / \mathrm{s}^{2}$ and the vibration in 2016 is $0.16 \mathrm{~m} / \mathrm{s}^{2}$; the reliable estimation of the main bearing temperature in 2015 is $48.1{ }^{\circ} \mathrm{C}$ and the temperature in 2016 is $48.4{ }^{\circ} \mathrm{C}$. Environmental temperature in both 2015 and 2016 is $5.8 \pm 0.2^{\circ} \mathrm{C}$ in the time interval of producing SCADA data for main bearing temperature. Take the estimation results from the data in 2015 as benchmark data, both criteria $\delta_{a}$ and $\delta_{t}$ are calculated. The results are $\delta_{a}=0.842$ and $\delta_{t}=1.006$. Both deviate from 1 thus seems to indicate the ageing effect on nacelle vibration and main bearing temperature in the past one year.

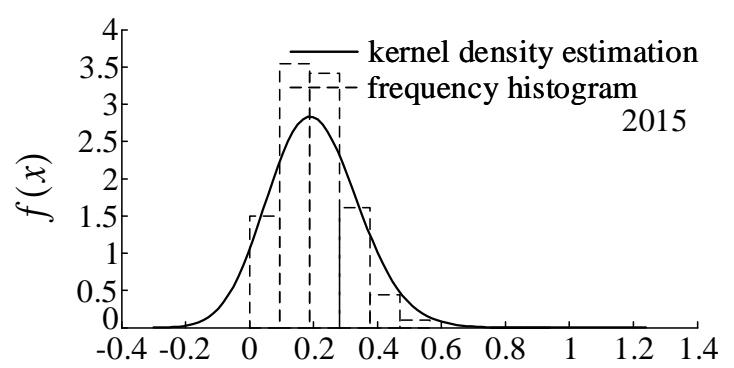

(a) Vibration acceleration $/ \mathrm{m} \cdot \mathrm{s}^{-2}$

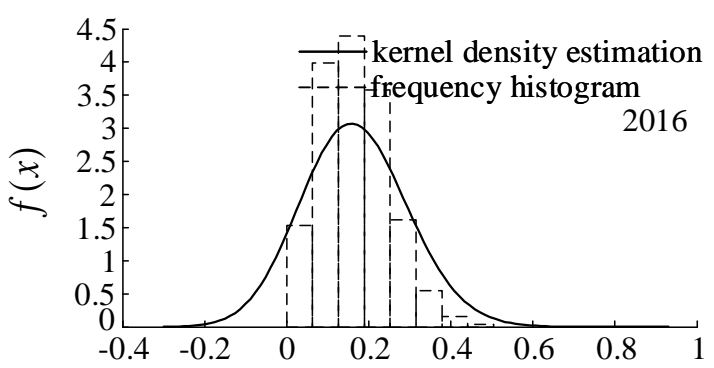

(b) Vibration acceleration $/ \mathrm{m} \cdot \mathrm{s}^{-2}$

Fig.10 Histogram and kernel density estimation of vibration acceleration

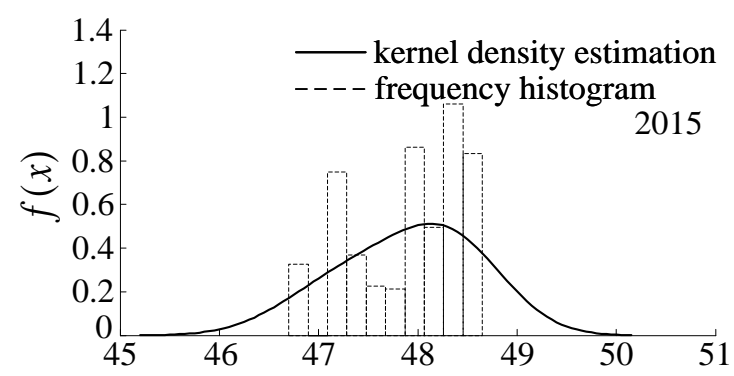

(a)

Temperature $/{ }^{\circ} \mathrm{C}$

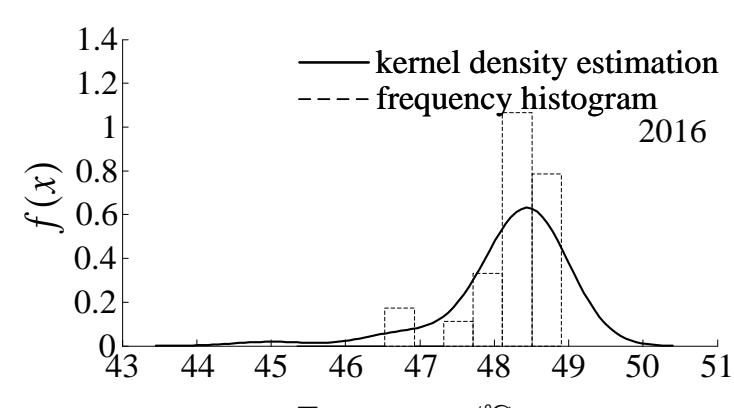

(b)

Temperature $/{ }^{\circ} \mathrm{C}$

Fig.11 Histogram and kernel density estimation of bearing temperature 
To facilitate further analysis, all ageing criterion calculation results are listed in Table 2.

462

463

\section{4}

465

Table 2. Calculation results for the unit \#1 wind turbine

\begin{tabular}{c|cccc}
\hline $\begin{array}{c}\text { Criterion } \\
\text { yalues }\end{array}$ & $\begin{array}{c}\text { Power } \\
\text { fluctuation }\end{array}$ & $C_{p}$ & Vibration & Temperature \\
\hline 2015 & 1 & 1 & 1 & 1 \\
2016 & 0.992 & 1.089 & 0.842 & 1.006 \\
\hline
\end{tabular}

From Table 2, it can be seen that the values of all four ageing criteria deviate from 1. During the service life of a wind turbine (normally 25-30 years), ageing will inevitably happen over time. However, the apparent ageing effect of the turbine should not be clearly observed within only one-year time. So, it can be said that separate analysis of individual ageing assessment criterion cannot lead to a reliable assessment of turbine ageing effect. The sum of the four criteria is 3.929, which is smaller than 4 thus is unreasonable because ageing is inevitable even if within oneyear time. Thus, it can be concluded that the conventional ageing assessment method proposed in Section 3.2 cannot lead to a reliable assessment of the ageing of the turbine. Therefore, the information fusion method proposed in Section 3.2 is applied to interpret the calculation results in Table 2. Substitute the calculated values of the four ageing criteria in Table 2 and the weighting factors in Table 1 into (19), has

$$
\begin{aligned}
\delta & =r_{1} \cdot \delta_{p}+r_{2} \cdot \delta_{C_{p}}+r_{3} \cdot \delta_{a}+r_{4} \cdot \delta_{t} \\
& =0.124+0.517+0.147+0.226 \\
& =1.014
\end{aligned}
$$

Obviously, such a result is more realistic and acceptable. According to (19), the value of the comprehensive ageing assessment criterion $\delta$ is equal to 1 in the absence of ageing. Eqn. (20) gives a calculation result of 1.014, which deviates from 1 by $1.4 \%$. Thus, it can be concluded that ageing of the turbine is small and ignorable over the course from 2015 to 2016.

In order to further demonstrate the reliability and robustness of the proposed ageing assessment method, the SCADA data collected for another wind turbine (called unit \#2) in the same wind farm are processed as well. The concept of the unit \#2 turbine is exactly same as the unit \#1 turbine and was installed also in 2011 . Then, the four criteria for ageing assessment are calculated as well and the results are listed in Table 3.

From Table 3, it is found that the values of all four ageing criteria deviate from 1 as well. But it is noticed that the value of vibration criterion is smaller than 1 , while the values of the other three criteria are larger than 1 . This makes it difficult to draw a reliable ageing assessment conclusion. To overcome this issue, the comprehensive ageing assessment criterion is calculated as well. The result is equal to 1.085 , which is a reasonable value to indicate the slight ageing problem of the wind turbine happening within one-year time. Thus, it can be concluded that in contrast to the individual ageing assessment criteria the comprehensive ageing assessment criterion is more effective to provide a reliable assessment of the ageing issues of wind turbines. 


\begin{tabular}{c|cccc} 
Criterion & $\begin{array}{c}\text { Power } \\
\text { fluctuation }\end{array}$ & $C_{p}$ & Vibration & Temperature \\
\hline 2015 & 1 & 1 & 1 & 1 \\
2016 & 1.167 & 1.158 & 0.876 & 1.048 \\
\hline
\end{tabular}

\section{Concluding remarks}

Unlike the previous effort that has been made to investigate the actual health condition and reliability issues in wind turbines, SCADA-based preliminary research was firstly conducted in this paper in order to perform an ageing assessment of a wind turbine. In the current practice of the wind farm operation and maintenance, the kind of issues has not attracted much interest because the majority of modern wind turbines in operation today are at their young ages. However, with the increase of their ages, the ageing issue will occur inevitably sooner or later. They are not linked to any type of fault. But they can lead to the frequent presence of faults and reliability issues, thus increased downtime and high wind turbine operation and maintenance cost. From this point of view, the research on the ageing issue of a wind turbine is of great importance to improve the life management of a wind turbine and maximize its economic return. In this paper, the ageing assessment research was started from discussing the SCADA parameters that potentially can be used for ageing assessment. Then, four ageing assessment criteria were developed in order to describe the ageing issues of wind turbines from different points of views and based on which, both a conventional and information fusion based ageing assessment methods were developed. Finally, the effectiveness of the proposed method in the ageing assessment was verified using real SCADA data collected from a wind farm. From the work shown above, it can be concluded that the proposed information fusion based method is indeed effective in assessing the ageing issues in a wind turbine, although further verification is still needed in the future.

Following this research, the proposed ageing assessment method will be further improved through optimizing the weighting factors by considering the views of more experts, and moreover, the method will be verified using more wind farm SCADA data. In addition, the ageing assessment of different concepts of wind turbines has not been considered in the research presented in this paper. In the future, different concepts of wind turbines will be distinguished when designing ageing assessment criteria and the influence of external environmental factors on turbine ageing will be considered as well. All new research achievements will be reported in separate papers.

\section{Acknowledgements}

This work reported in this paper is supported by the National Natural Science Foundation of People's Republic of China (grant number 51475160, 11632011, 11472103) and State Scholarship Fund (grant number 201408430267), Hunan Provincial Natural Science Foundation (grant number 2016JJ5024) and Scientific Research Fund of Hunan Provincial Education Department (grant number 15B084).

\section{References}

[1] AMIRAT Y, BENBOUZID M E H, AL-AHMAR E, et al. A brief status on condition monitoring and fault diagnosis in wind energy conversion systems[J]. Renewable and Sustainable Energy Reviews, 2009, 13(9): 2629-2636

[2] WATSON S J, XIANG B J, YANG W, et al. Condition monitoring of the power output of wind turbine generators 
using wavelets[J]. Energy Conversion, IEEE Transactions on, 2010, 25(3): 715-721

[3] YANG W, TAVNER P J, CRABTREE C J, et al. Cost-effective condition monitoring for wind turbines[J]. Industrial Electronics, IEEE Transactions on, 2010, 57(1): 263-271

[4] CHEN J, PAN J, LI Z, et al. Generator bearing fault diagnosis for wind turbine via empirical wavelet transform using measured vibration signals[J]. Renewable Energy, 2016, 89: 80-92

[5] BESNARD F, BERTLING L. An approach for condition-based maintenance optimization applied to wind turbine blades[J]. Sustainable Energy, IEEE Transactions on, 2010, 1(2): 77-83

[6] LIU X, GAO Z. Takagi-sugeno fuzzy modelling and robust fault reconstruction for wind turbine systems[C].Industrial Informatics (INDIN), 2016 IEEE 14th International Conference on, 2016: IEEE: 492-495.

[7] FISCHER K, BESNARD F, BERTLING L. Reliability-centered maintenance for wind turbines based on statistical analysis and practical experience[J]. Energy Conversion, IEEE Transactions on, 2012, 27(1): 184-195

[8] GUO H, WATSON S, TAVNER P, et al. Reliability analysis for wind turbines with incomplete failure data collected from after the date of initial installation[J]. Reliability Engineering \& System Safety, 2009, 94(6): 1057-1063

[9] ARABIAN-HOSEYNABADI H, ORAEE H, TAVNER P. Failure modes and effects analysis (FMEA) for wind turbines[J]. International Journal of Electrical Power \& Energy Systems, 2010, 32(7): 817-824

[10] STAFFELL I, GREEN R. How does wind farm performance decline with age?[J]. Renewable energy, 2014, 66: 775786

[11] GAO Z, CECATI C, DING S X. A survey of fault diagnosis and fault-tolerant techniques—part I: Fault diagnosis with model-based and signal-based approaches[J]. IEEE Transactions on Industrial Electronics, 2015, 62(6): 37573767

[12] GAO Z, CECATI C, DING S X. A survey of fault diagnosis and fault-tolerant techniques-part II: Fault diagnosis with knowledge-based and hybrid/active approaches[J]. IEEE Transactions on Industrial Electronics, 2015, 62(6): 3768-3774

[13] KUSIAK A, LI W. The prediction and diagnosis of wind turbine faults[J]. Renewable Energy, 2011, 36(1): 16-23

[14] FENG Y, QIU Y, CRABTREE C J, et al. Use of SCADAA and CMS signals for failure detection and diagnosis of a wind turbine gearbox[C].European Wind Energy Conference and Exhibition, Sheffield, 2011: 17-19.

[15] KIM K, PARTHASARATHY G, ULUYOL O, et al. Use of SCADAA data for failure detection in wind turbines[C].ASME 2011 5th International Conference on Energy Sustainability, Washington, DC, 2011: 2071-2079.

[16] YONGJIE Z, DONGFENG W, JUNYING Z, et al. Research on early fault diagnostic method of wind turbines[J]. TELKOMNIKA Indonesian Journal of Electrical Engineering, 2013, 11(5): 2330-2341

[17] ZAHER A, MCARTHUR S, INFIELD D, et al. Online wind turbine fault detection through automated SCADAA data analysis[J]. Wind Energy, 2009, 12(6): 574-593

[18] SCHLECHTINGEN M, SANTOS I F, ACHICHE S. Wind turbine condition monitoring based on SCADAA data using normal behavior models. Part 1: System description[J]. Applied Soft Computing, 2013, 13(1): 259-270

[19] SCHLECHTINGEN M, SANTOS I F. Wind turbine condition monitoring based on SCADAA data using normal behavior models. Part 2: Application examples[J]. Applied Soft Computing, 2014, 14: 447-460

[20] YANG W, COURT R, JIANG J. Wind turbine condition monitoring by the approach of SCADAA data analysis[J]. Renewable Energy, 2013, 53: 365-376

[21] LOU J, SHAN K, XU J. A new condition monitoring method for wind turbines based on power curve model[J]. International Journal of Control and Automation, 2016, 9(3): 393-408

[22] YANG W, TAVNER P J, CRABTREE C J, et al. Wind turbine condition monitoring: Technical and commercial challenges[J]. Wind Energy, 2014, 17(5): 973-693

[23] FENG Y, QIU Y, CRABTREE C J, et al. Monitoring wind turbine gearboxes[J]. Wind Energy, 2013, 16(5): 728-740

[24] YANG H, SHEN W, XU H, et al. Prediction of the wind turbine performance by using BEM with airfoil data extracted from CFD[J]. Renewable Energy, 2014, 70: 107-115

[25] LANZAFAME R, MESSINA M. Fluid dynamics wind turbine design: Critical analysis, optimization and application 


(1)

(3)

of BEM theory[J]. Renewable Energy, 2007, 32(14): 2291-2305

[26] DAI J C, HU Y P, LIU D S, et al. Aerodynamic loads calculation and analysis for large scale wind turbine based on combining BEM modified theory with dynamic stall model[J]. Renewable Energy, 2011, 36(3): 1095-1104

[27] DAI J-C, HU Y-P, LIU D-S, et al. Modelling and analysis of direct-driven permanent magnet synchronous generator wind turbine based on wind-rotor neural network model [J]. Proceedings of the Institution of Mechanical Engineers, Part A: Journal of Power and Energy, 2012, 226(1): 62-72

[28] HANSEN A, MICHALKE G. Modelling and control of variable-speed multi-pole permanent magnet synchronous generator wind turbine[J]. Wind Energy, 2008, 11(5): 537-554

[29] VALENCIAGA F, FERNANDEZ R D. Multiple-input-multiple-output high-order sliding mode control for a permanent magnet synchronous generator wind-based system with grid support capabilities[J]. Renewable Power Generation, IET, 2015, 9(8): 925-934

[30] MARTINEZ J, BERNABINI L, PROBST O, et al. An improved BEM model for the power curve prediction of stall regulated wind turbines[J]. Wind Energy, 2005, 8(4): 385-402

[31] LAKSHMANAN K, ORTNER R, RYABKO D. Improved regret bounds for undiscounted continuous reinforcement learning[C].Proceedings of the 32nd International Conference on Machine Learning, Lille, 2015: 524-532.

[32] LIU Z, SHI R, SHEN L, et al. Unsupervised salient object segmentation based on kernel density estimation and twophase graph cut[J]. Multimedia, IEEE Transactions on, 2012, 14(4): 1275-1289

[33] BESSA R J, MIRANDA V, BOTTERUD A, et al. Time adaptive conditional kernel density estimation for wind power forecasting[J]. Sustainable Energy, IEEE Transactions on, 2012, 3(4): 660-669

[34] DAI J, LIU D, WEN L, et al. Research on power coefficient of wind turbines based on SCADAA data[J]. Renewable Energy, 2016, 86: 206-215

[35] WEI J, XUAN Y. Equations for calculating thermophysical properties of moist air[J]. Journal of HV\&AC, 1996, 26(3): 16-19

\section{8}




\section{Figure Caption:}

619 Fig.1 Power control structure of wind turbines when wind speed is above the rated wind speed

620 Fig.2 Mass-spring-damping model of the nacelle

621 Fig.3 Influence factors of main bearing temperature

622 Fig.4 Estimated output power fluctuation through kernel density analysis

623 Fig.5 Relationship between rotor speed and power

624 Fig.6 wind speed and power fluctuation in a sampling interval

625 Fig.6a Wind speed

626 Fig.6b Power fluctuation

627 Fig.7 Histogram and kernel density estimation of power fluctuation

628 Fig.8 Histogram and kernel density estimation of power coefficient

629 Fig.9 Histogram and kernel density estimation of vibration acceleration

630 Fig.10 Histogram and kernel density estimation of bearing temperature

631

632

\section{Table Caption:}

634 Table 1. Weighting factors assigned to the four ageing assessment criteria

635 Table 2. Calculation results for the unit \#1 wind turbine

636 Table 3. Calculation results for the unit \#2 wind turbine 